\title{
CONFLICTIVIDAD Y FUNDAMENTACIÓN DE LA ÉTICA
}

\section{Reseña Bibliográfica}

\section{Gustavo Salerno}

\section{RICARDO MALIANDI: Ética, dilemas y convergencias: cuestiones de la identidad, la globalización y la tecnología, Buenos Aires: Biblos - UNLa, 2006, 253 pp.}

El cambio de milenio ha traído consigo la emergencia de variadas problemáticas, entre las que se destacan las concernientes a la identidad, la globalización y la tecnología. Ellas, en realidad, no son nuevas, ya que tienen su germen en procesos fluctuantes aunque sostenidos en el tiempo; pero se han impuesto en la actualidad como ámbitos que la reflexión ética no puede eludir. Lo acuciante radica en determinar si los conflictos, que se enraízan en el ethos y que son parte constitutiva de éste, pueden encontrar en la filosofía práctica una tematización detenida, problematizadora y propositiva. Con Maliandi ello tiene ocasión: parte de la concepción de que para que pueda hablarse de moral o ética, precisamente tiene que haber un problema, un interrogante que se le aparezca a la razón como un desafío y a la vez como una exigencia, la de buscar una solución o "salida".

Así como Maliandi sostiene que la conflictividad no es algo aleatorio o circunstancial a las relaciones sociales, tampoco lo es su empeño por contribuir al esclarecimiento de sus distintas aristas. Dedicado a ello durante los últimos treinta años, aporta ahora una significativa sistematización de sus análisis, a los que agrega una sobria presentación de su peculiar posición en torno a una vía posible para la resolución, minimización y regulación de los conflictos. En efecto, en este nuevo trabajo la identidad, la globalización y la tecnología aparecen como problemáticas que resultan ejemplos del entretejimiento asimismo problemático del ethos, a partir del cual la propuesta de una "ética convergente" se muestra como un decisivo aporte para su estudio.

La obra en cuestión tiene su antecedente inmediato en la publicación de la tercera edición, corregida y aumentada, de Ética: conceptos y problemas (Biblos, 2004). Se trata de un texto ineludible en el propósito de acercarse a 
las nociones mínimas de la disciplina, y puede tenerse ahora también como una aproximación al enfoque propio del autor. Ello se justifica especialmente a partir del agregado de un extenso capítulo (que representa la cuarta parte de la nueva versión) dedicado a "Fundamentación, conflictividad y convergencia". Luego de repasar los avatares a los que se han enfrentado ( $y$ que enfrentan) las propuestas de fundamentar la ética (relativismo y escepticismo, como negaciones de tal posibilidad; metafísica y empirismo, como intentos fracasados), se propone una "alternativa crítica", representada por el paradigma de la convergencia entre la disposición a tener en cuenta la experiencia y la comprensión de que los fundamentos no pueden extraerse de ella, ya que deben servir precisamente para explicarla. Vale decir, para Maliandi los conflictos no son sólo problemas morales, sino también éticos: la conflictividad, evidente en el plano fáctico, atañe también a la fundamentación de la ética. A las ediciones anteriores (1990 y 1993) se han agregado un índice de nombres, otro de temas, y una extensa bibliografía que contribuyen a la riqueza y accesibilidad del texto.

Pero es en Ética, dilemas y convergencias donde la propuesta de una "ética convergente" aparece ocupando el puesto central de la exposición, mostrando sus rendimientos en el abordaje de las cuestiones ya mencionadas. La noción de "convergencia" es la clave que requiere ser detenidamente considerada para la comprensión del puesto de Maliandi en el pensamiento actual. Definida por la vía negativa, ella no es un eclecticismo o una mera yuxtaposición de tesis; positiva y propositivamente incluye, inicialmente, los siguientes significados: 1) el de una aproximación entre la ética material de los valores (Scheler y, principalmente, Hartmann) y la ética del discurso (Apel); 2) el rasgo básico de una ética que defiende una pluralidad de principios y la exigencia de maximizar la armonía entre ellos. El supuesto es para Maliandi, en uno y otro caso, el de que desde Kant todo intento de fundamentar las normas morales más allá de la razón (metafísica, empírica o científicamente) representa un "anacronismo" y conduce al extravío del radical logro kantiano: la conciencia de sí que es capaz de alcanzar la ética normativa. Por ello, de la primera acepción antedicha se sigue el reconocimiento a la inevitabilidad de los conflictos $\mathrm{y}$, a la vez, la necesidad de una fundamentación fuerte, a priori (de la que se deriva un $a$ priori de la conflictividad). Por otro lado, en el segundo sentido, hay una crítica al rigorismo kantiano y al monopricipalismo apeliano, al destacar la búsqueda de convergencia entre cuatro principios cardinales (en 
correspondencia con la bidimensionalidad de la razón): universalidad individualidad (conflictividad sincrónica) y conservación - realización (conflictividad diacrónica).

El desarrollo de estos y otros postulados de la ética convergente se encuentran a lo largo de la obra en relación con el tratamiento de los tres ejes de análisis. La primera parte, "Dilemas de la identidad" (pp. 19-61), presenta la idea de que tanto la génesis de la conciencia de la identidad sincrónica (autoconocimiento y autocrítica en individuos; cohesión y pluralismo en grupos) como de la diacrónica (coherencia y creatividad; tradición y renovación, respectivamente) son comunicativas, dialógicas. En el caso de los derechos humanos, que Maliandi también aborda, no se requiere de argumentación adicional a su afirmación, ya que se los considera condición de posibilidad de todo argumento. Sin embargo, identidades y derechos están desplegados invariablemente sobre una trama de relaciones conflictivas producto de la exacerbación de una de las dimensiones. La ética convergente sostiene que, cuando en la discusión argumentativa el interlocutor deja de lado su posición egocéntrica (y deja de comprender a los otros como oponentes), es posible alcanzar una convergencia crítica, y que cuando los principios entran en pugna debe recurrirse a un metaprincipio de convergencia, que reemplaza la exigencia teleológica por la exigencia del cumplimientos parciales, composibles (en sentido leibniziano). Hacia el cierre de esta parte inicial Maliandi realiza una sobria presentación del estudio de Hartmann respecto a los "actos trascendentes emocionales". Este recurso permite al autor sumar la consideración de otro enfrentamiento que atañe a la reflexión ética: "el conflicto básico entre lo racional y lo emocional, entre el logos y el pathos" (p. 59).

La segunda parte, "Dilemas de la globalización y la tecnología" (pp. 63-146) comienza con una explicación "antropológica" del lugar en el cual aparece inserta la complejidad que traen consigo aquellas. Maliandi se refiere a una "dialéctica" de desequilibrios y compensaciones que transita por tres estadios: una primigenia desadaptación al medio ambiente (plano ecológico), una reparación no natural sino artificial a través de la técnica (plano etológico), la cual sobrepasa, no obstante, su propósito inhibitorio y provoca un nuevo intento de equilibrio a través de la cultura y la moral (plano ético). De tal modo, puede advertirse que: hay en la historia así considerada un proceso continuo de rupturas y equilibrios; que estos últimos, a su vez, tienen un carácter ambivalente, con aspectos axiológicos positivos y 
negativos (manifiestamente en la técnica, capaz de provocar desastres cuando no se la limita, pero también presente en la ética, que enfrenta a sistemas muchas veces irreconciliables); y que la globalización no es sólo un proceso económico sino uno característicamente humano, de modo que resulta una temática ante la cual la ética ya no puede permanecer ajena.

Así, para Maliandi, se vuelve imperioso asumir que "la necesidad de una ética de la globalización se infiere directamente de la evidencia de que se están violando las más elementales normas de justicia social" (p. 78), y la conciencia de ello representa la urgencia de efectivizar recursos compensatorios. Ni la tecnofilia (la veneración ilimitada) ni la tecnofobia (la oposición obcecada) deben dar lugar al escepticismo ni al relativismo ético. En tal sentido, Maliandi encuentra relevante la propuesta de la ética del discurso de un principio interpretable como un "indicador procedimental" para la validación de normas situacionales (la exigencia de resolver los conflictos de interés mediante discursos prácticos en los que se busque el consenso de todos los afectados). Esta "metanorma" posee carácter universal, a priori, y si bien tiene el mérito de superar el rigorismo kantiano, para Maliandi "representa una perspectiva necesaria pero insuficiente" (p. 92). Como ya se ha dicho, la ética convergente cree posible pensar en un a priori de la conflictividad, no sólo en cuanto parte esencial de las interrelaciones sociales, sino también en cuanto al reconocimiento de una pluralidad de principios. Con otras palabras, al admitir un a priori tal se expresa la voluntad de minimizar los conflictos (evitándolos, resolviéndolos o regulándolos) y se reconoce que todo lo social está conflictivamente estructurado.

Asimismo, la ética convergente interpreta los cuatro principios bioéticos propuestos por Beauchamp y Childress como formas específicas de lo que llama "principios cardinales". El aporte significativo de Maliandi se halla en la fundamentación y sistematización de unos y otros, en correspondencia con la bidimensionalidad de la razón y las estructuras conflictivas. De ello obtiene, mediante una aguda argumentación que resulta imposible resumir aquí, cuatro principios bio-tecno-éticos. precaución, exploración, no discriminación y respeto a la diversidad genéticas. Aquí también se hace presente la tesis de incomposibilidad de los óptimos (Leibniz), propiciando la postulación del "metaprincipio" que exige procurar el máximo equilibrio posible en la observación de los cuatro que se han fundamentado. 
La segunda parte concluye con la enfatización de la necesidad y posibilidad de una "ética global", por ejemplo tal como ya se ha entrevisto en Küng o Walzer, aunque no a través de la base empírica de la que parten. Según Maliandi en la ética del discurso encontramos el recurso "elemental" y "mínimo" de validez universal (su princpio procedimental), al que la ética convergente continúa y reformula en los sentidos ya referidos. Sin embargo, más allá de esta indicación, es preciso destacar la tesis (sin dudas sugerente y provocativa) respecto a que "la razón -y particularmente la razón en su uso práctico- puede expresarse también de un modo extraargumentaivo o, para decirlo con mayor precisión, de un modo preargumentativo" (p. 129). Esta posición, creemos, lleva a Maliandi hasta los límites de la pragmática trascendental apeliana, enfoque que asume un a priori del lenguaje $\mathrm{y}$ que Maliandi también admite al entender refutado el solipsismo metódico que caracterizó a la filosofía moderna). Ya en Volver a la razón (1997, p. 69) se encuentra una alusión a aquello, lo cual generó críticas de parte de otros destacados defensores de la ética del discurso (por ejemplo en nuestro medio, Julio De Zan). Como sea, en este nuevo trabajo la tesis remite al hecho de que se considera que "una acción es racional no sólo si está justificada sino ya por el mero hecho de ser justificable", de modo que puede entenderse que es justificable (y, por ende, racional) antes del empleo de argumentos. ¿En qué consiste la "justibicabilidad" de una acción?: para Maliandi, en la espontánea oposición a lo conflictivo. De tal modo, puede interpretar que la "norma básica" apeliana no contiene sólo una exigencia, sino dos: 1) que los conflictos sean resueltos, y 2) que lo sean mediante argumentos. El caso aquí, entonces, es que ya la primera exigencia puede considerarse racional. Las derivaciones de esta indicación son sumamente relevantes, y sólo podemos instar con esta mención a conocerlas y ponderarlas críticamente de manera directa.

La tercera y última parte, "Perspectivas convergentes" (pp. 147-240), contiene un detenido análisis del platonismo axiológico de Hartmann y de sus posibles aportes para la ética convergente. Además, se desarrolla con más amplitud la diferencia entre variadas formas de relativismo y el reconocimiento de un pluriprincipalismo, no irrestricto sino limitado a cuatro principios. La posición de Maliandi, una vez más, pude comprenderse en tanto se ha asumido un a priori de la conflictividad también en el nivel de los principios (podemos decir: al nivel de los "deberes", aspecto inadvertido en la ética kantiana). La "salida" puede ser entendida como un desideratum, y 
ello porque resulta no pocas veces que más de un principio es lesionado, "en cuyo caso el metaprincipio es interpretable como la demanda de que los daños sean equitativos" (p. 195).

Ya hacia el final de la obra se abordan cuestiones concernientes no exclusivamente a la problemática de la fundamentación sino que se realiza una tipología de paradigmas de aplicabilidad ética: 1) de la autoridad; 2) de la situación; 3) del rigorismo; 4) de la provisionalidad; 5) de restricción compensada (en referencia a la "parte B" de la ética de Apel); y 6) de la convergencia. No obstante las críticas formuladas en diversos pasajes de la obra, Maliandi dedica todo un capítulo a destacar la importancia que la filosofía de Apel tiene para un concepto actual de democracia.

El texto se cierra con el señalamiento de la necesidad de contar con el agregado de una serie de principios de equidad discursiva, a los efectos de "contribuir a una minimización de las perturbaciones introducidas cuando el acatamiento a las demás reglas es sólo simulado” (p. 237). Maliandi intenta reformular los "principios de justicia" de Rawls a partir de los presupuestos de la pragmática trascendental y de la ética convergente, posibilitando de tal modo "un equilibrio de poder" y, además, "una peculiar reciprocidad discursiva, consistente en que cada interlocutor puede, en principio, 'ayudar" al otro o a los otros a 'alumbrar' sus propias opiniones o “ideas"” (p. 239).

Esta primera edición, cuenta con una amplia bibliografía de cada uno de los aspectos que se abordan, y un índice de temas y de nombres que facilitan el manejo de un texto central para quienes sienten la necesidad de replantearse críticamente los más serios problemas de nuestro tiempo.

Ética, dilemas $y$ convergencias contiene aquella ordenación y sistematización que sólo son posibles de parte de quien ha llevado sus análisis hasta lo más obvio y profundo del que es su objeto. Si a ello se agrega el empleo de un lenguaje claro y, fundamentalmente, el desarrollo de la original propuesta de Maliandi para enfrentar lo acuciance sin perderse en ello, se tiene la idea de un texto ineludible y de infinito provecho. 